\title{
Great Saphenous Vein Diameter at Different Regions and its Relation to Reflux
}

\author{
SAID I. EL MALLAH, M.D.*; YAHIA MOHAMMED AL-KHATEEP, M.D.* and \\ KAREEM HADY KAMEL, M. S c. ** \\ The Department of Vascular Surgery, Faculty of Medicine, Menoufia University* and El-Sahel Teaching Hospital**, Egypt
}

\begin{abstract}
Background: Great saphenous vein incompetence is involved in the majority of cases of varicose disease. Standard pre-interventional assessment is required to decide the treatment modalities. GSV diameter measured at sapheno-femoral junction, proximal thigh, distal thigh, knee, proximal leg, distal leg. Analysis done to find at which diameter size the reflux expected to occur.
\end{abstract}

Aim of Study: To investigate a possible correlation of GSV diameters measured at sapheno-femoral junction, proximal thigh, distal thigh, below knee and at mid leg and there relation to the reflux.

Patient and Methods: Study involved 100 limbs from outpatient vascular clinic, GSV diameter measurement at the sapheno-femoral junction, at the proximal thigh, at the distal thigh, below the knee, mid leg in correlation to reflux.

Results: SFJ reflux (group I) at $7.16 \pm 2.30 \mathrm{~mm}$, proximal thigh (group II) at $6.60 \pm 1.89 \mathrm{~mm}$, distal thigh (group IIIa) at $6.12 \pm 1.63 \mathrm{~mm}$, knee (group IIIb) at $5.78 \pm 1.60 \mathrm{~mm}$, proximal leg (group IV) at $4.6 \pm 1.24 \mathrm{~mm}$, and mid leg (group V) at $3.59 \pm$ $1.16 \mathrm{~mm}$.

Conclusions: Measurement at six sites revealed higher sensitivity and specificity to predict reflux, GSV diameter correlates with reflux.

Key Words: Varicose veins - Great saphenous vein - Vein diameter at different regions - Comparison of clinical trials.

\section{Introduction}

VARICOSE disease affects one third of the population and has an impact on morbidity, quality of life and health costs. The Great Saphenous Vein (GSV) is involved in the majority of cases [1]

Symptoms include distressing feelings of swelling and heaviness and frank pain. Objective findings are meandering and dilated superficial veins, oedema, dermatitis, dermatosclerosis and skin

Correspondence to: Dr. Kareem Hady Kamel, E-Mail: kareem hadykamel@yahoo.com ulceration. These manifestations are the consequence of long standing volume overload and hypertension in cutaneous veins caused by wall distension, valve incompetence, blood flow abnormality and secondary phenomena such as allergy and inflammation [2].

Treatment is directed towards abolition of venous reflux. For decades, this has been accomplished by ligation of the GSV at its junction with the Common Femoral Vein (CFV) and vein stripping, first of the entire GSV, later limited to its refluxing part. In the last decades, alternative options became available, such as haemodynamic surgery, [3] endovenous thermal ablation [4] and foam sclerotherapy [5]. Duplex ultrasound is widely employed to guide these interventions.

Comparison of treatment modalities requires exact documentation of the clinical, anatomical and functional situation prior to whichever treatment is given [6].

Reflux and GSV diameter measurements may serve as surrogate parameters for disease severity and provide criteria for planning interventions and monitoring outcome. GSV diameters have been assessed at various sites with different techniques: Upright or recumbent patient position, cross sectional or longitudinal imaging, and various sites of interest [2].

A consensus-based manual recommends two sites where GSV diameters should be measured, 3 $\mathrm{cm}$ below the SFJ and mid-thigh, [6] while earlier studies used a site $15 \mathrm{~cm}$ below the SFJ [7]. Thus far, neither the clinical relevance of these measurements nor the relative significance of the site of measurement has been clarified. In this thesis, investigation done to find a possible correlation 
of GSV diameters measured at different regions and there relation to the reflux.

Various investigations have been carried out to establish the duration of reflux standing which correlates with venous disease [8-10].

In general, no difference was found between durations of 0.5 and $1 \mathrm{~s}$. In other words, the number of legs determined to suffer from reflux did not alter significantly depending on whether the duration of reflux was set at 0.5 or $1 \mathrm{~s}$.

Although the cut-off value was set at $0.5 \mathrm{~s}$, a definition of reflux set at $1 \mathrm{~s}$ may avoid diagnosing pathology at borderline values when there are no clinical signs.

Reflux duration decreases with severity of disease and has been described as the time taken for the anti-gravitational mechanisms of the leg to fail [11].

\section{Venous Arterial Flow Index (VAFI):}

The first non-invasive option for a quantitative measurement of haemodynamic parameters is duplex ultrasound. This can measure the velocity of blood flow in a vein. This parameter can be used to calculate the volume flow $(1 / \mathrm{min})$ by multiplying the average blood flow velocity $(\mathrm{cm} / \mathrm{s})$ by the crosssectional area of the vein.

Cross-sectional area $=v \mathrm{X} \mathrm{r} 2$ or $v \mathrm{Xd} 2 / 4$. Once the diameter $(\mathrm{d}=2 \mathrm{r})$ is measured by positioning the cursors on the machine, the Time-Averaged Mean Velocity (TAMV) and Volume Flow (VF) are automatically calculated and displayed on the screen.

The common femoral vein can be taken as a representative vessel from which the volume flow can be measured. Volume flow can also be measured in the saphenous vein [12].

Conclusions can then be made on the venous haemodynamics draining the affected leg. Arterial parameters should be included in the quantitative assessment since they influence venous haemodynamics. For this reason, a ratio can be calculated for the venous and arterial volume flow in the common femoral vein and the common femoral artery, respectively. This ratio is called the Venous Arterial Flow Index (VAFI).

Volume Flow (VF) is measured in the relaxed, lying patient, with the leg rotated slightly outwards and the head supported on a pillow. While the measurements are taken, it is important that the patient should breathe calmly and that the vein should not be compressed by excessive pressure of the probe on the skin. The diameters of the common femoral artery and common femoral vein are then measured in transverse view. Volume flow is measured in longitudinal view.

Artery it is recommended to measure the flow over several pulses to calculate the Time-Averaged Mean Velocity (TAMV). This function is usually configured in the machine.

Vein the typical flow pattern is slow and relatively constant, modulated by respiration. It should be measured over several seconds and then the average calculated as with the artery.

Since the artery and the vein flow in opposite directions, the flow in the vein appears as a negative value. It must be treated as positive for calculating the VAFI. The flow velocity is given in $\mathrm{m} / \mathrm{s}, \mathrm{m} / \mathrm{min}$ or $\mathrm{cm} / \mathrm{s}$, at the site of the measured vessel diameter (d). The Volume Flow (VF) in each vessel is calculated from the diameters and flow velocities using the following formula:

$$
\begin{gathered}
\mathrm{VF}\left[\mathrm{cm}^{3} / \mathrm{s}\right]=\text { TAMV }[\mathrm{cm} / \mathrm{s}] \mathrm{X} \mathrm{II} \mathrm{d} / 4\left[\mathrm{~cm}^{2}\right] \\
1 \mathrm{~cm}^{3}=1 \mathrm{ml} \text { area is II } \mathrm{X} \mathrm{r}^{3} \text { or II } \mathrm{X} \mathrm{d}^{3} / 4 .
\end{gathered}
$$

If the volume flow in the common femoral vein and common femoral artery are designated $\mathrm{VFa}$ and $\mathrm{VFv}$, respectively, then

$$
\mathrm{VAFI}=\mathrm{VFv}[\mathrm{ml} / \mathrm{min}] / \mathrm{VFa}[\mathrm{ml} / \mathrm{min}]
$$

In subjects with healthy veins, the VAFI is $<1.0$. In patients with haemodynamically significant impairment, the VAFI increases $>1.2$. It can even increase up to 2.0 [13]. This means that the flow in the femoral vein is much higher than the arterial inflow into the leg. This occurs when there is a recirculation loop. The VAFI is also very useful for measuring the haemodynamic situation before and after intervention. The influence of intervention on haemo-dynamics is seen after only a few days when the high preoperative values return to normal. The non-invasive nature of ultrasound in measuring VF is a clear advantage compared to invasive measurement techniques.

\section{Validation of the VAFI:}

The index was measured in patients with different venous diseases under different conditions. It was shown that with primary varicose veins, significantly higher values were measured than those found in healthy subjects [13]. A similar pattern was found in patients with postthrombotic syndrome compared to healthy subjects [13] and that the level of the VAFI values correlated with the clinical severity of the disease. In the above 
studies, subjects with healthy veins were found to have an average VAFI $\leq 1.0$. This may be interpreted to mean that there is a point of equivalence between arterial inflow per unit of time and the corresponding venous outflow per unit of time. The high VAFI values found in varicose patients may be an index of recirculation which normalises after intervention. With respect to the reliability of the measurement results, it was shown that the VAFI remained stable both during uninterrupted examination for $1 \mathrm{~h}$ and over 3 consecutive days [13]. The VAFI is a repeatable, sensitive parameter for venous haemodynamics which has been confirmed with modern phasecontrast MR techniques [14].

The great saphenous vein at the proximal thigh was more uniform, easier to measure and more representative as a single measurement point. The average diameter in subjects with healthy veins was $7.5 \mathrm{~mm}( \pm 1.8)$ at the sapheno-femoral junction and $3.7 \mathrm{~mm}( \pm 0.9)$ in the proximal thigh. In subjects with reflux, the average diameter was $10.9 \mathrm{~mm}$ $( \pm 3.9)$ at the sapheno-femoral junction and $6.3 \mathrm{~mm}$ $( \pm 1.9)$ in the proximal thigh. The diameter did not correlate with the Hach Class [2].

Diameter measurements should be taken in a transverse image. For the reasons mentioned above, it is preferable to measure the diameter in the thigh, $10-15 \mathrm{~cm}$ from the groin, in a segment where the walls of the great saphenous vein run parallel and there are neither inflows nor outflows.

\section{Patients and Methods}

It was a practitioner initiated prospective study performed in a vein clinic in Cairo and Menoufia from Jan. 2018 to Jan. 2019. Survey of the GSV was undertaken in consecutive outpatients who consulted with the suspicion or presence of a primary venous disorder.

The protocol was accepted by the Ethics Committee of the Menoufia University, Egypt.

Inclusion criteria:

- Primary varicose vein.

- Age: $18 \mathrm{y}-60$.

- Eligible legs were included irrespective of the findings on the other leg, this study involved 100 limbs.

\section{Exclusion criteria:}

- Secondary varicose vein.

- Recurrent varicose vein.

- Deep venous reflux.
- Acute disorders (thrombosis/phlebitis/cellulitis).

- Lymphedema, pregnancy.

- Below 18y, above 60y.

Assessment: History taking will involve previous DVT, surgery, any comorbidity, clinical examination general and local including CEAP classification, Duplex u/s.

\section{Examination:}

- History taking.

- Clinical examination: General and local.

- Clinical findings were documented: CEAP classification.

- Protocol examination of varicose vein with duplex U/S: (Standing position).

Superficial system: SFJ, GSV reflux, vein diameter: Transverse, SFJ distal to terminal valve $(2 \mathrm{~cm})$, proximal thigh $(15 \mathrm{~cm}$ after $\mathrm{SFJ})$, distal thigh (just above medial trochanter $2 \mathrm{~cm}$ ), below the knee (proximal leg) (below medial trochanter $2 \mathrm{~cm}$ ), mid leg (below medial trochanter $10 \mathrm{~cm}$ ), anterior accessory saphenous vein, posterior accessory saphenous vein, sapheno-popliteal junction, small saphenous vein.

Deep system: IVC, CIV and EIV, common femoral vein, femoral vein and deep femoral vein, popliteal vein, posterior tibial vein and anterior tibial vein.

Duplex ultrasound examinations were performed by a single investigator with a Toshiba Apolio 400 colour-coded duplex scanner fitted with a $7.5-\mathrm{MHz}$ linear probe and $2-5 \mathrm{MHz}$ curved probe $[15,16]$.

Steps of examination: Asses patency and competency:

Standing position: SSV, intersaphenous V, PASV, SPJ, Calf v, GSV (SFJ, proximal thigh, distal thigh, knee, proximal leg, distal leg), AASV, SASV.

Lying position: CFV, SFJ, FV, DEEP FV, POP V, PTV, ATV, EIV, CIV and CIV diameter, IVC.

The GSV was examined in the standing position applying toe movements, manual compression and decompression as well as Valsalva manoeuvres to assess orthograde flow and reflux. Reflux lasting longer than 1s was considered pathologic [17].
Patients were classified into 5 groups: Table 
Table (1): Classification of patients in the study.

\begin{tabular}{|c|c|}
\hline & \\
\hline Group I & - SFJ reflux. \\
\hline Group II & - Proximal thigh GSV reflux ( $15 \mathrm{~cm}$ after SFJ). \\
\hline Group III & $\begin{array}{l}\text { - A: Distal thigh (just above medial trochanter } \\
2 \mathrm{~cm} \text { ). } \\
\text { - B: Knee GSV reflux. }\end{array}$ \\
\hline Group IV & $\begin{array}{l}\text { - Below knee GSV reflux (proximal leg) (below } \\
\text { medial trochanter } 2 \mathrm{~cm} \text { ). }\end{array}$ \\
\hline Group V & $\begin{array}{l}\text { - Mid leg GSV reflux (below medial trochanter } \\
10 \mathrm{~cm} \text { ). }\end{array}$ \\
\hline
\end{tabular}

No assessment was made of dilated distal branch veins and eventually incompetent perforator veins. Excluded lower limbs with reflux through the AASV, PASV and SSV. Trunkal GSV was examined only.

Clinical findings were documented according to the highest CEAP (clinical, etiologic, anatomic and pathophysiologic) class. Legs range from teleangiectasies (C 1) to active venous ulcers (C6).
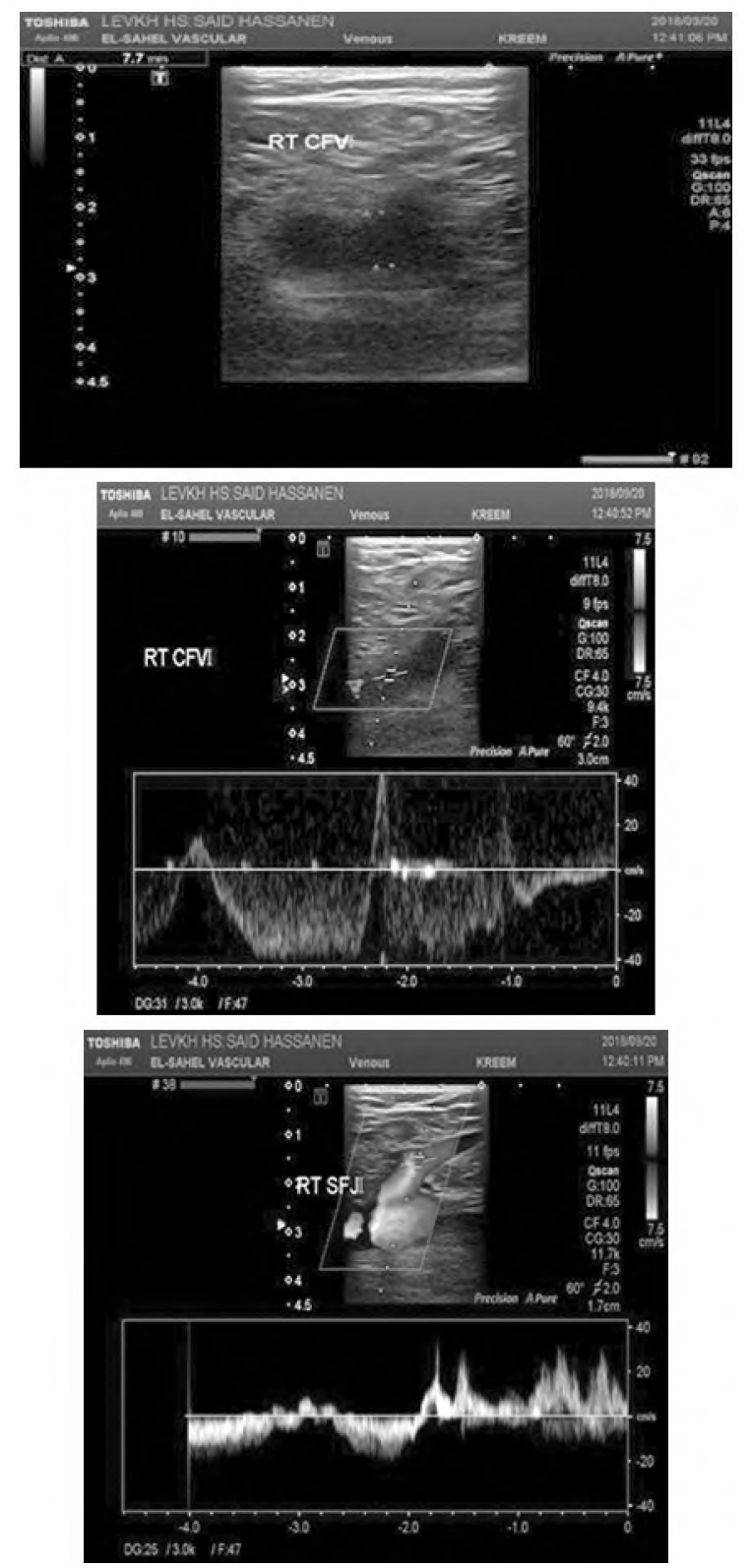
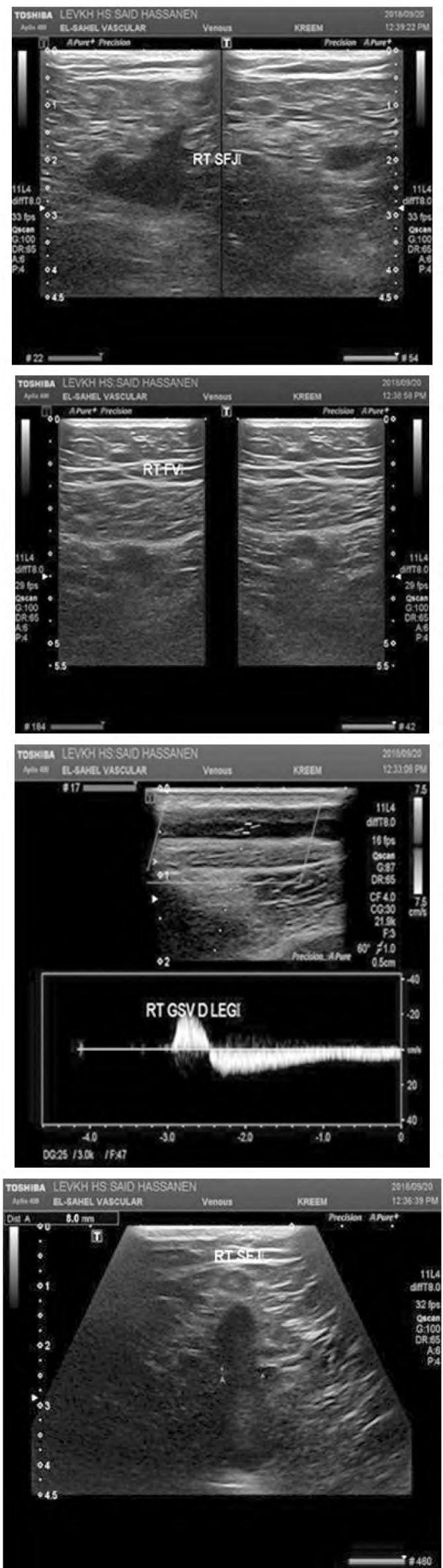

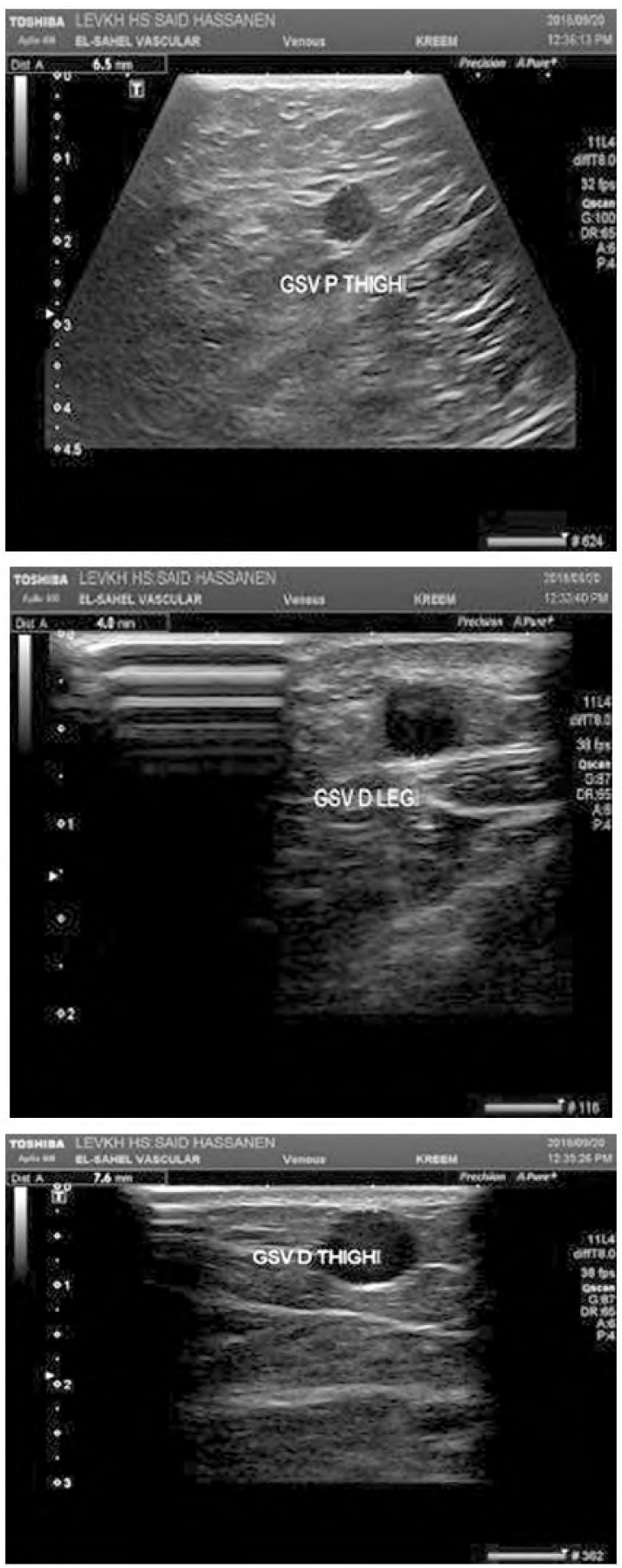

Fig. (1): Case examination of lower limb venous system during standing and supine position.

In all cases, the aetiology was primary (Ep) and pathophysiology reflux (Pr). The anatomy was varicose GSV trunk with or without branch varices.

Vein diameters were measured holding the probe transversely with no pressure. Duplicate measurements were taken at five sites: At the SFJ distal to the terminal valve and $15 \mathrm{~cm}$ below the junction. (This site, chosen by CHIVA (Conservative ambulatory haemodynamic management of Varicose veins) group members, shows parallel walls of the GSV and is located above the junction of the most proximal branch veins $[18,19]$. At the knee, at the proximal leg and mid leg.

\section{Results}

Patients were randomized 100 lower limbs included with trunkal GSV reflux or segmental reflux.

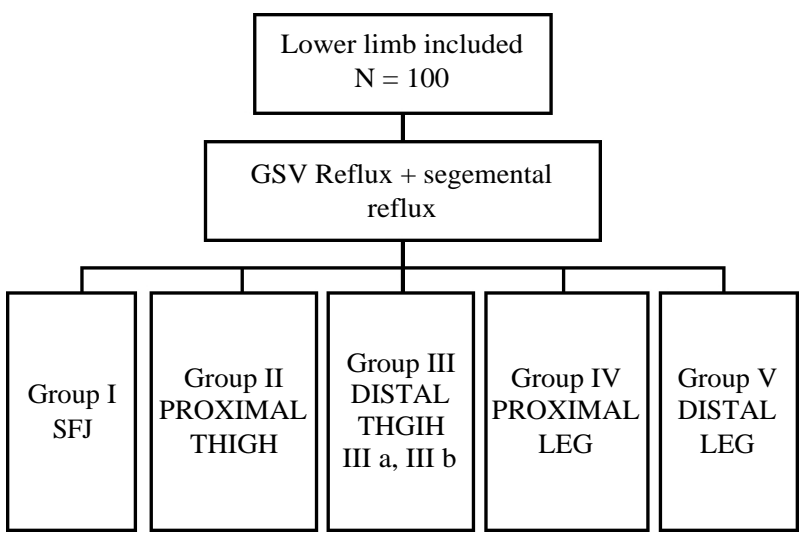

Fig. (2): Study flow chart.

Demography of patients, median age was 36y, female was $70 \%$ of lower limb examined, weight range from $50-130 \mathrm{~kg}$ with BMI 28-30 C2 and C3 represent $74 \%$ of patients, correlations were found with body weight in each group and BMI but not with height (Table 2).

Table (2): Demography of the patients.

\begin{tabular}{ll}
\hline & No.=100 \\
\hline Age: & \\
Mean \pm SD & $35.74 \pm 7.76$ \\
Range & $18-52$ \\
Gender: & \\
Female & $70(70.0 \%)$ \\
Male & $30(30.0 \%)$ \\
Weight: & \\
Mean \pm SD & $91.78 \pm 16.39$ \\
Range & $50-130$ \\
CEAP: & \\
C1 & $2(2.0 \%)$ \\
C2 & $32(32.0 \%)$ \\
C3 & $42(42.0 \%)$ \\
C4 & $18(18.0 \%)$ \\
C6 & $6(6.0 \%)$ \\
\hline
\end{tabular}

Clinical findings of a venous disorder were teleangiectases (C1) were found in 34\%, branch varices (C2) in $32 \%$, oedema (C3) in $42 \%$, dermatosclerosis (C4) in $18 \%$ and active venous ulcer (C6) in 6\% Fig. (3). 
CEAP

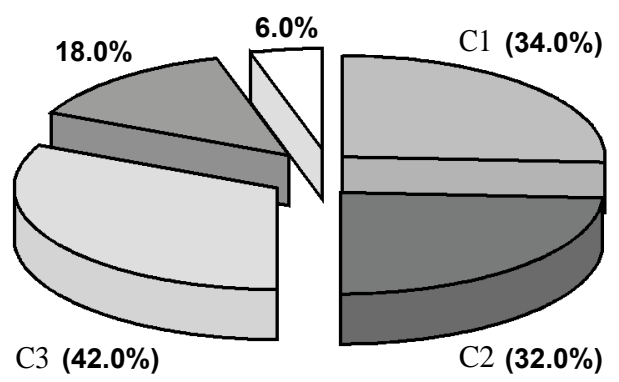

Fig. (3): Clinical findings of venous disorder.

In patients with SFJ reflux (group I), reflux occur at $(7.16 \pm 2.30 \mathrm{~mm})$ (Table 3$)$.

Table (3): SFJ reflux.

\begin{tabular}{lccccc}
\hline SFJ & $\begin{array}{c}\text { Not reflux } \\
\text { No.=46 }\end{array}$ & $\begin{array}{c}\text { Reflux } \\
\text { No.=54 }\end{array}$ & $\begin{array}{c}\text { Test } \\
\text { value }\end{array}$ & $\begin{array}{c}p \text { - } \\
\text { value }\end{array}$ & Sig. \\
\hline Mean \pm SD & $5.66 \pm 1.59$ & $7.16 \pm 2.30$ & -3.743 & $<0.001$ & HS \\
Range & $3.50-9.50$ & $4.00-14.00$ & & & \\
\hline
\end{tabular}

$p$-value $>0.05$ : Non Significant (NS).

$p$-value $<0.05$ : Significant $(\mathrm{S})$.

$p$-value $<0.01$ : Highly Significant (HS).

$\bullet$ Independent $t$-test.

SFJ

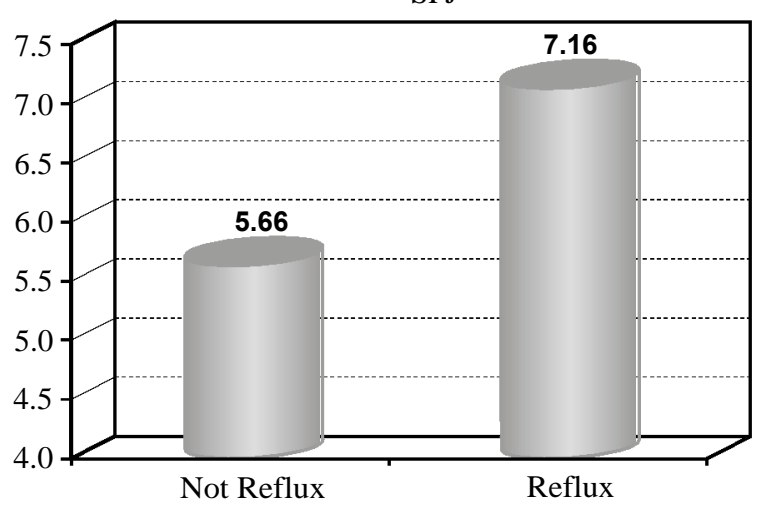

Fig. (4): SFJ diameter at which reflux occur.

In patients with proximal thigh reflux (group II), reflux occur at $(6.60 \pm 1.89 \mathrm{~mm})$.

Table (4): GSV proximal thigh.

\begin{tabular}{|c|c|c|c|c|c|}
\hline $\begin{array}{l}\text { GSV Prox } \\
\text { thigh }\end{array}$ & $\begin{array}{c}\text { Not reflux } \\
\text { No. }=42\end{array}$ & $\begin{array}{c}\text { Reflux } \\
\text { No. }=58\end{array}$ & $\begin{array}{c}\text { Test } \\
\text { value }\end{array}$ & $\begin{array}{c}p- \\
\text { value }\end{array}$ & Sig. \\
\hline Mean \pm SD & $4.38 \pm 0.93$ & $6.60 \pm 1.89$ & -7.031 & $<0.001$ & HS \\
\hline
\end{tabular}

$p$-value $>0.05$ : Non Significant (NS).

$p$-value $<0.05$ : Significant (S)

$p$-value <0.01: Highly Significant (HS).

$\bullet:$ Independent $t$-test.

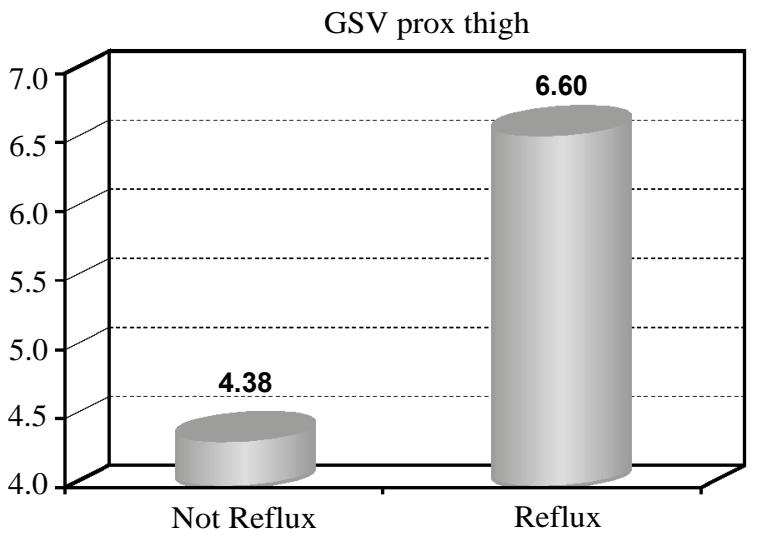

Fig. (5): GSV proximal thigh diameter at which reflux occur.

In patients with distal thigh reflux (group IIIa), reflux occur at $(6.12 \pm 1.63 \mathrm{~mm})$.

Table (5): GSV distal thigh.

\begin{tabular}{lccccc}
\hline GSV & $\begin{array}{c}\text { Not reflux } \\
\text { DIST thigh }\end{array}$ & $\begin{array}{c}\text { Reflux } \\
\text { No. }=40\end{array}$ & $\begin{array}{c}\text { Test } \\
\text { value }\end{array}$ & $\begin{array}{c}p \text { - } \\
\text { value }\end{array}$ & Sig. \\
\hline Mean \pm SD & $\begin{array}{c}4.19 \pm 1.04 \\
\text { Range }\end{array}$ & $\begin{array}{c}6.12 \pm 1.63 \\
\text { 2.50-6.50 }\end{array}$ & $3.10-9.619$ & $<0.001$ & HS \\
\hline
\end{tabular}

$p$-value $>0.05$ : Non Significant (NS).

$p$-value $<0.05$ : Significant (S).

$p$-value $<0.01$ : Highly Significant (HS).

$\bullet:$ Independent $t$-test.

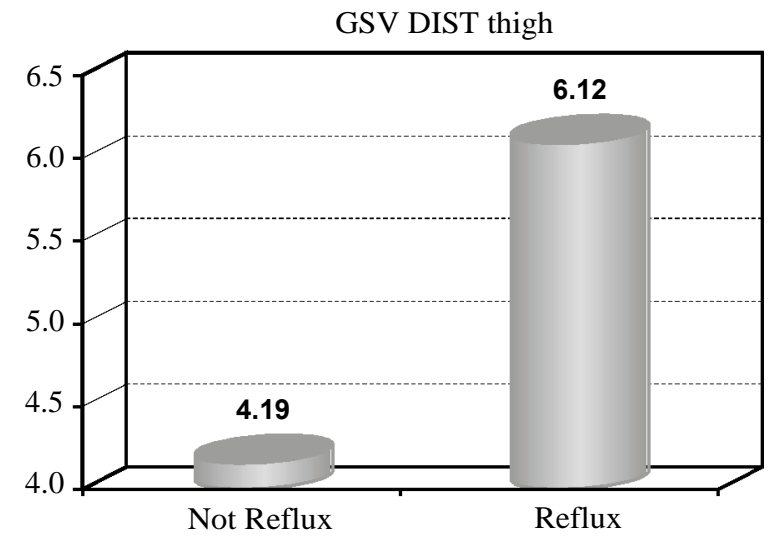

Fig. (6): GSV distal thigh diameter at which reflux occur.

In patients with knee reflux (group IIIb), reflux occur at $(5.78 \pm 1.60 \mathrm{~mm})$.

Table (6): GSV knee region.

\begin{tabular}{lccccc}
\hline GSV knee & $\begin{array}{c}\text { Not reflux } \\
\text { No. }=40\end{array}$ & $\begin{array}{c}\text { Reflux } \\
\text { No.=60 }\end{array}$ & $\begin{array}{c}\text { Test } \\
\text { value }\end{array}$ & $\begin{array}{c}p \text { - } \\
\text { value }\end{array}$ & Sig. \\
\hline Mean \pm SD & $3.66 \pm 0.82$ & $5.78 \pm 1.60$ & -7.711 & $<0.001$ & HS \\
Range & $2.30-5.50$ & $3.60-11.00$ & & & \\
\hline
\end{tabular}

$p$-value $>0.05$ : Non Significant (NS).

$p$-value $<0.05$ : Significant $(\mathrm{S})$

$p$-value <0.01: Highly Significant (HS).

$\bullet$ Independent $t$-test. 


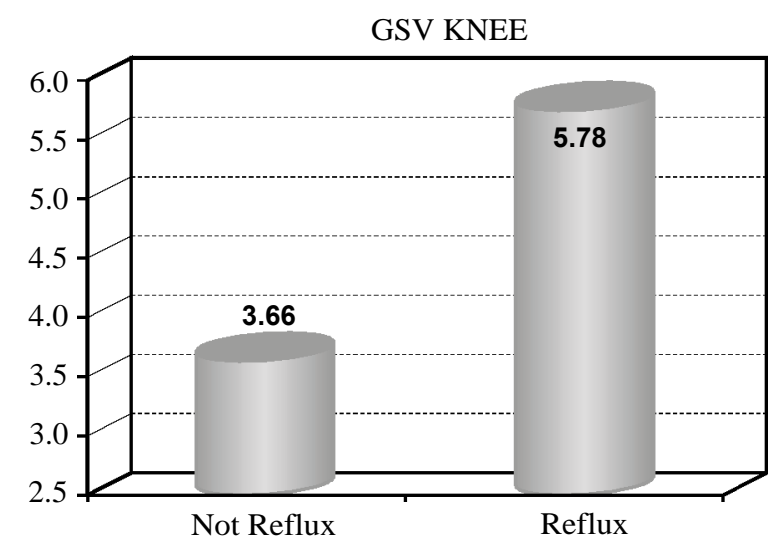

Fig. (7): GSV knee diameter at which reflux occur.

In patients with proximal leg (group IV), reflux occur at $(4.6 \pm 1.24 \mathrm{~mm})$.

Table (7): GSV proximal leg.

\begin{tabular}{lccccc}
\hline GSV & $\begin{array}{c}\text { Not reflux } \\
\text { No.=40 }\end{array}$ & $\begin{array}{c}\text { Reflux } \\
\text { No.=60 }\end{array}$ & $\begin{array}{c}\text { Test } \\
\text { value }\end{array}$ & $\begin{array}{c}p \text { - } \\
\text { value }\end{array}$ & Sig. \\
\hline Mean \pm SD & $3.09 \pm 0.74$ & $4.60 \pm 1.24$ & -6.933 & $<0.001$ & HS \\
Range & $2.00-4.80$ & $2.80-7.50$ & & & \\
\hline
\end{tabular}

$p$-value $>0.05$ : Non Significant (NS).

$p$-value $<0.05$ : Significant $(\mathrm{S})$.

$p$-value <0.01: Highly Significant (HS).

$\bullet$ Independent $t$-test.

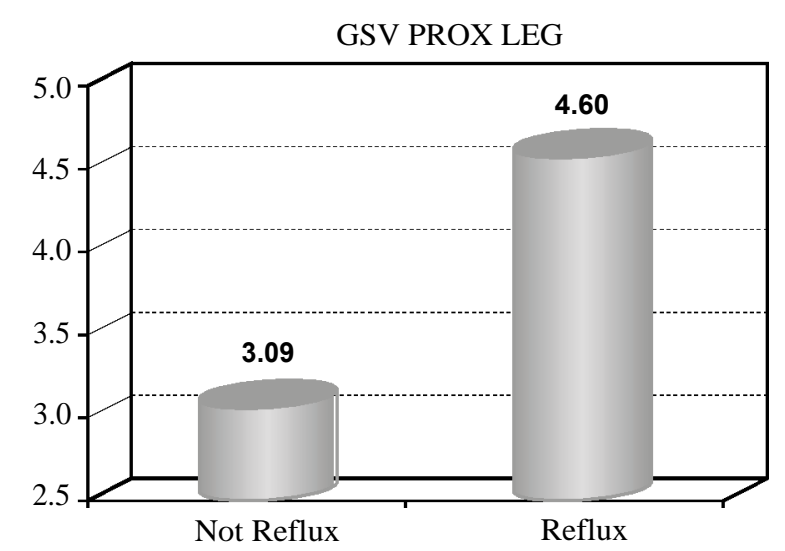

Fig. (8): GSV proximal leg diameter at which reflux occur.

In patients with mid leg reflux (group V), reflux occur at $(3.59 \pm 1.16 \mathrm{~mm})$.

Table (8): GSV mid leg.

\begin{tabular}{lccccc}
\hline GSV & $\begin{array}{c}\text { Not reflux } \\
\text { MID leg }\end{array}$ & $\begin{array}{c}\text { Reflux } \\
\text { No. } 68\end{array}$ & $\begin{array}{c}\text { Test } \\
\text { value }\end{array}$ & $\begin{array}{c}p \text { - } \\
\text { value }\end{array}$ & Sig. \\
\hline Mean \pm SD & $2.56 \pm 0.46$ & $3.59 \pm 1.16$ & -6.396 & $<0.001$ & HS \\
Range & $1.50-3.80$ & $1.90-6.00$ & & & \\
\hline
\end{tabular}

$p$-value $>0.05$ : Non Significant (NS).

$p$-value $<0.05$ : Significant $(\mathrm{S})$.

$p$-value $<0.01$ : Highly Significant (HS).

$\because$ Independent $t$-test.

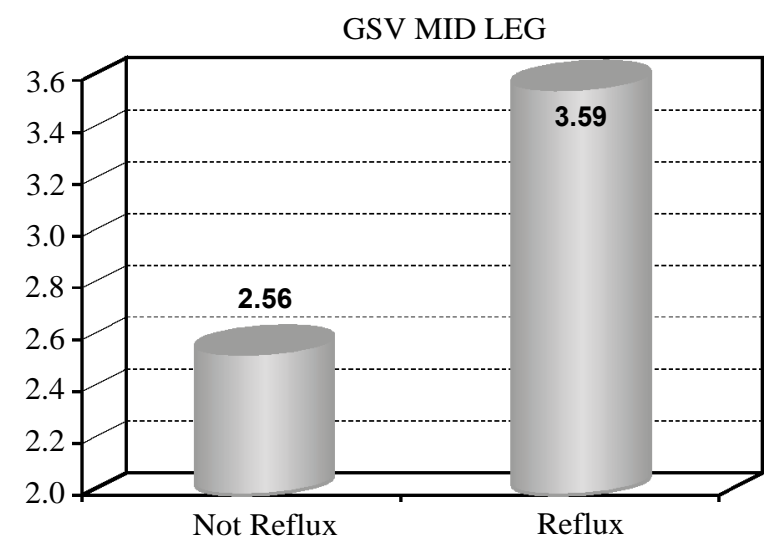

Fig. (9): GSV mid leg diameter at which reflux occur.

Vein diameters were larger in the presence of reflux, compared with its absence, GSV diameters were assessed with regard to their value to predict reflux, curves were used to assess the relative performance of the five sites of measurement.

Sensitivity and specificity are calculated for thresholds at the mean: Fig. (9):

- Cut of point at SFJ $>5.7 \mathrm{~mm}$ with sensitivity $77.7 \%$.

- Cut of point at proximal thigh $>7 \mathrm{~mm}$ with sensitivity $44.4 \%$.

- Cut of point at distal thigh $>5.5 \mathrm{~mm}$ with sensitivity $60 \%$.

- Cut of point at knee $>4.2 \mathrm{~mm}$ with sensitivity $86.6 \%$.

- Cut of point at proximal leg $>3.5 \mathrm{~mm}$ with sensitivity $73 \%$.

- Cut of point at distal leg $>3 \mathrm{~mm}$ with sensitivity $56 \%$.

CFV was screened to make a relation between the diameter and reflux also: (Table 9): CFV diameter).

Sensitivity and specificity are calculated for thresholds at the CFV: Cut of point $>10.5 \mathrm{~mm}$ with sensitivity $77.8 \%$.

100 limbs included, SFJ reflux (group I) at $7.16 \pm 2.30 \mathrm{~mm}$, proximal thigh (group II) at $6.60 \pm$ $1.89 \mathrm{~mm}$, distal thigh (group IIIa) at $6.12 \pm 1.63 \mathrm{~mm}$, knee (group IIIb) at $5.78 \pm 1.60 \mathrm{~mm}$, proximal leg (group IV) at $4.6 \pm 1.24 \mathrm{~mm}$, and mid leg (group V) at $3.59 \pm 1.16 \mathrm{~mm}$.

Measurement at six sites revealed higher sensitivity and specificity to predict reflux. 
SFJ
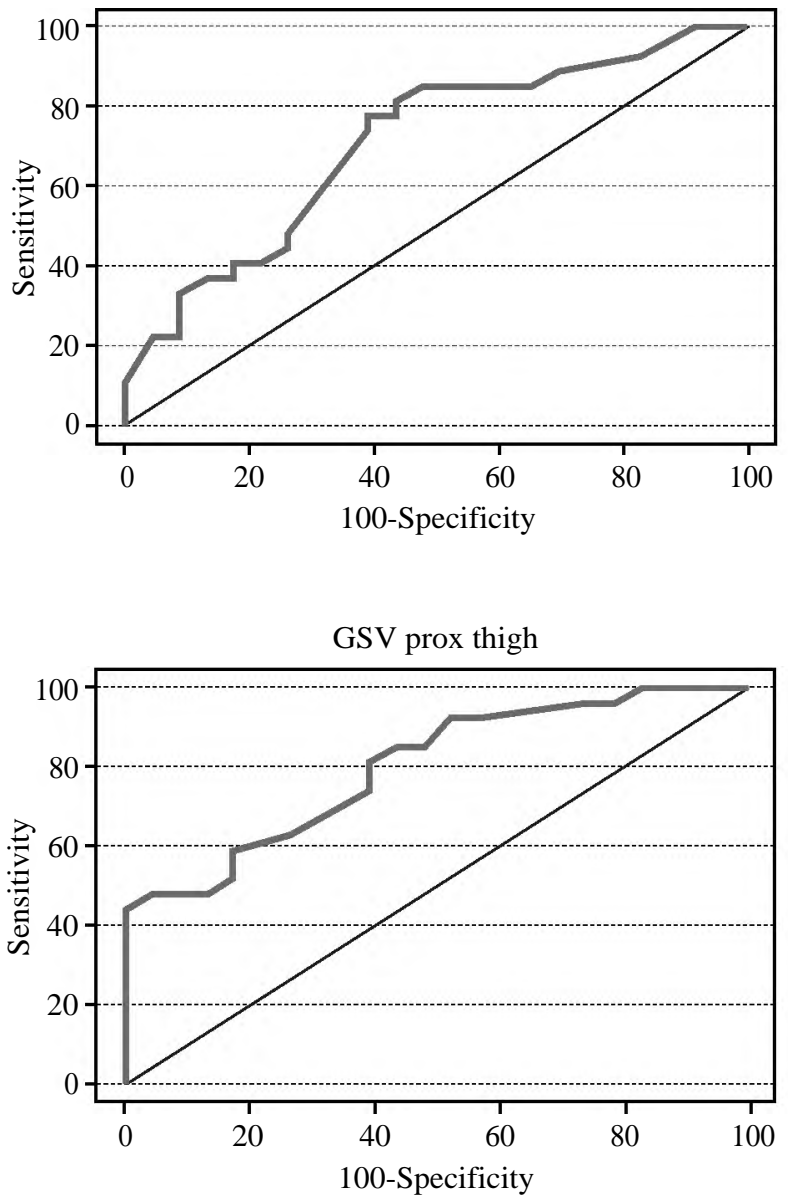

GSV prox leg

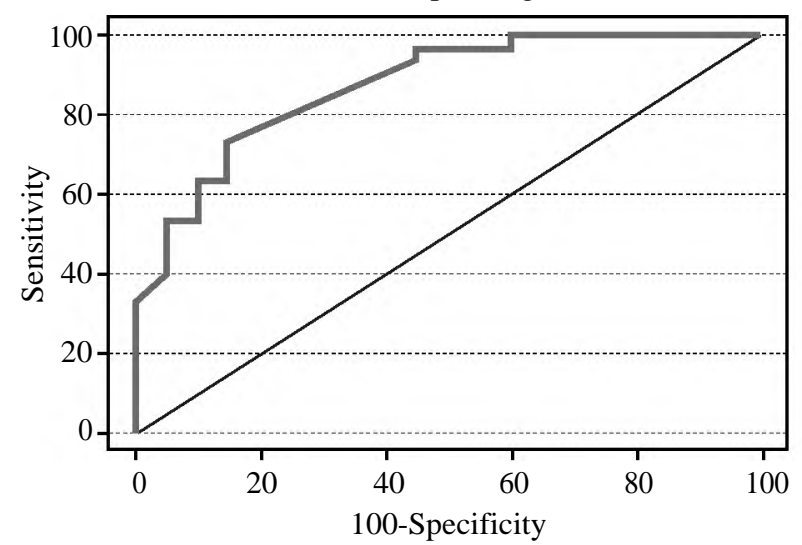

GSV knee

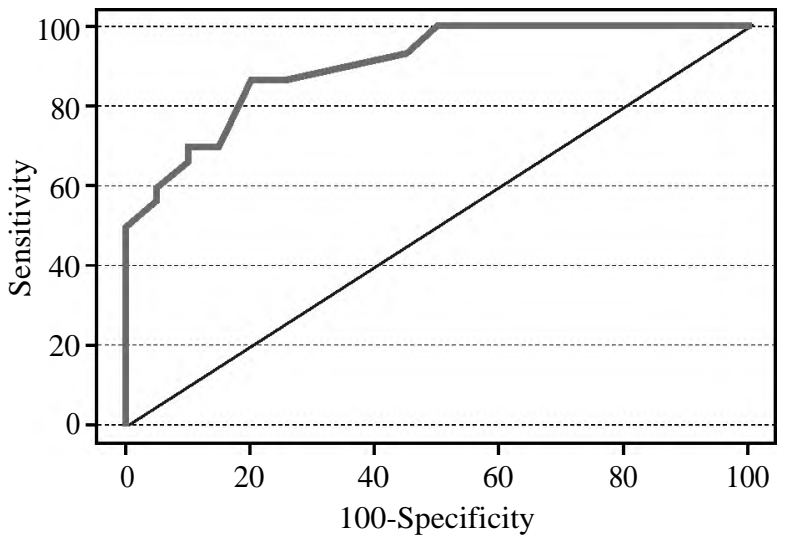

GSV dist thigh

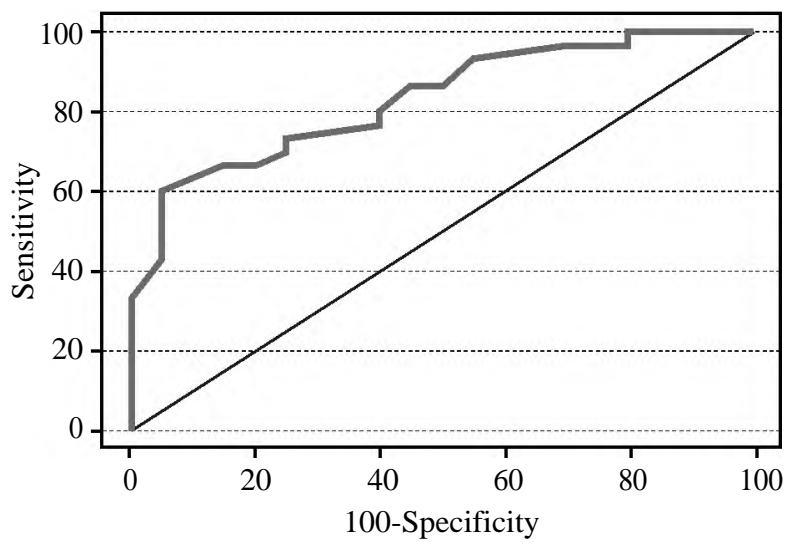

GSV distal leg

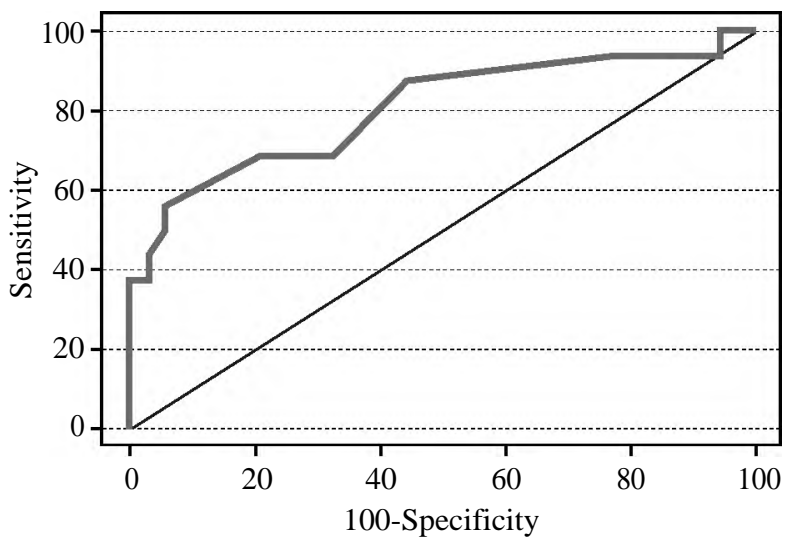

Fig. (10): Sensitivity and specificity are calculated for thresholds at the mean. 
Table (9): CFV diameter.

\begin{tabular}{lccccc}
\hline $\begin{array}{l}\text { CFV } \\
\text { diameter }\end{array}$ & $\begin{array}{c}\text { Not reflux } \\
\text { No.=64 }\end{array}$ & $\begin{array}{c}\text { Reflux } \\
\text { No.=36 }\end{array}$ & $\begin{array}{c}\text { Test } \\
\text { value }\end{array}$ & $\begin{array}{c}p \text { - } \\
\text { value }\end{array}$ & Sig. \\
\hline Mean \pm SD & $9.28 \pm 2.52$ & $11.51 \pm 1.28$ & -4.965 & $<0.001$ & HS \\
Range & $4.00-15.00$ & $9.00-14.00$ & & & \\
\hline
\end{tabular}

$p$-value $>0.05$ : Non Significant (NS).

$p$-value $<0.05$ : Significant $(\mathrm{S})$.

$p$-value <0.01: Highly Significant (HS).

$\bullet:$ Independent $t$-test.

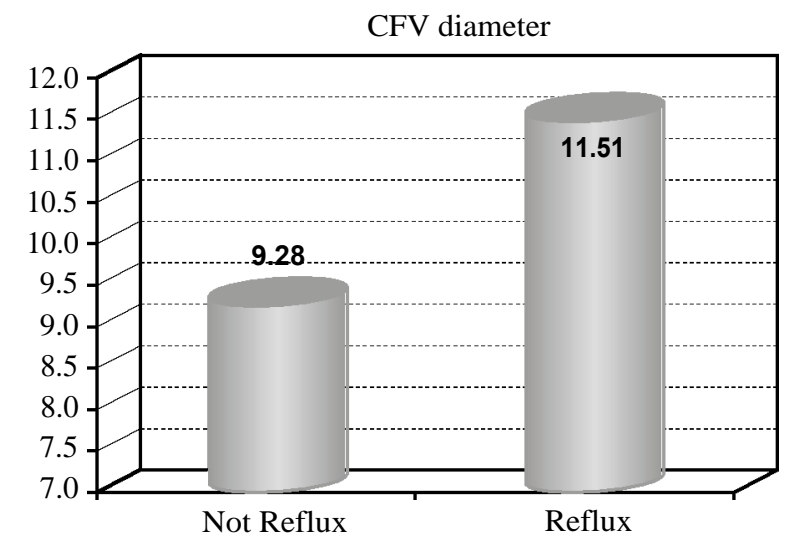

Fig. (11): CFV diameter at which reflux occur.

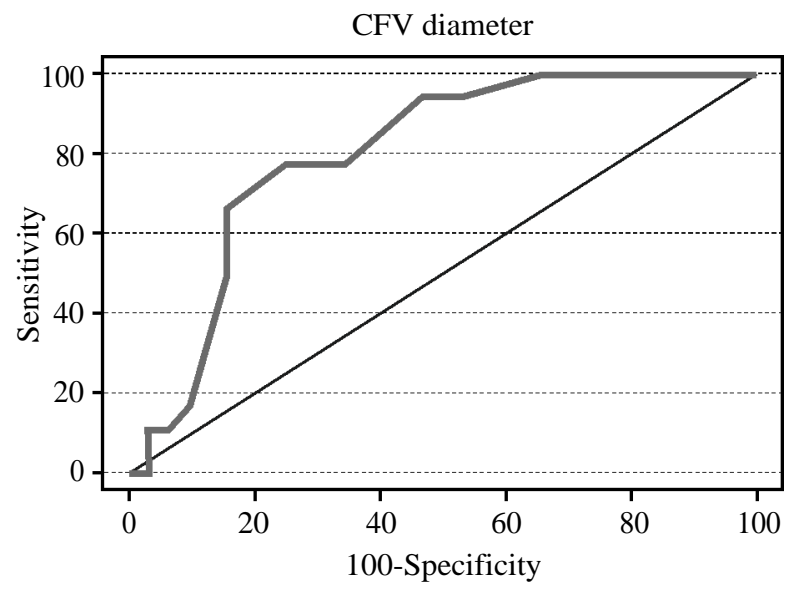

Fig. (12): CFV diameter sensitivity and specificity.

\section{Discussion}

Comparison of treatment modalities requires exact documentation of the clinical, anatomical and functional situation in each patient using standardised and validated techniques. However, even the recommendations of the Union Internationale de Phlébologie (UIP) regarding measurement of GSV diameter at different sites lack proper validation [15], diameter measurement at the PT seems to have some advantages as compared with measurement at the SFJ, which is a landmark easily identified with ultrasound. While GSV reflux in the groin is readily identified measurement of vein diameter right there is challenging for several reasons [20]
The curvature of the inguinal GSV renders adjustment of the ultrasound probe exactly perpendicular to the vein axis difficult. Further, the shape of the vein is influenced by joining epigastric, pudendal and accessory veins and eventual aneurysmatic dilatations caused by deep venous refluxes. Thus, diameter assessment in the groin appears less reliable [20]

The proximal thigh site $15 \mathrm{~cm}$ below the $\mathrm{SFJ}$ is located in the truncal portion of GSV where the vein is cylindrical and largely devoid of joining branches. The site is also well accessible and diameter measurements can be taken reliably [20]

The CHIVA Group measures diameters $15 \mathrm{~cm}$ distal to the SFJ because the PT site allows outcome assessment, as their treatment strategy leaves the GSV trunk in situ even when crossectomy is performed $[18,19]$

Data revealed a debatable finding: GSV diameter, venous haemodynamics [refilling times in photoplethysmography (PPG)] and clinical disease class did not differ whether reflux was above knee only or above and below knee. The finding is in disagreement with the understanding that the length of reflux in the GSV would have an influence on disease severity [21-23].

The correlation between the two measurement sites permitted calculation of a conversion factor used to review selected publications. It disclosed a wide range of diameters in patients worked up for interventions with different techniques (Table 10). The data suggest that some studies included patients with minor disease. The same may be true for a recent study that found no correlation between GSV diameter and quality of life. The reported diameters were within the limits of the control subjects of this study [24]

Diameter assessment at the PT seems suitable for stratification of patients allocated to future interventional trials as well as for outcome evaluation. With more data available it may also become an argument in the discussion of treatment options with patients, which is not the case at the moment. (Mendoza et al., 2012).

Study by Mendoza et al., 2012:

- Measurements were took at the SFJ as proposed by the UIP and compared it with measurements at the PT as used and published by the CHIVA group because no data on the mid thigh point have been published until 2010 . 
- Measurement at the PT as compared to measurement at the SFJ demonstrated higher accuracy and both higher sensitivity and specificity for venous disease class as well as for prediction of reflux. Thus, diameter measurement at the PT may develop as a surrogate parameter for specific clinical situations.

- Results: Of 182 legs, 60 had no GSV reflux (controls; group I), 51 had above-knee GSV reflux only (group II) and 71 had GSV reflux above and below knee (group III). GSV diameters in group
I measured $7.5 \mathrm{~mm}( \pm 1.8)$ at the SFJ and $3.7 \mathrm{~mm}$ $( \pm 0.9)$ at the PT. In groups II and III, they measured $10.9 \mathrm{~mm}( \pm 3.9)$ at the SFJ and $6.3 \mathrm{~mm}( \pm 1.9)$ at the PT $(p<0.001$ each).

- Measurement at the PT revealed higher sensitivity and specificity to predict reflux and clinical class.

- Concluded that GSV diameter correlates with clinical class, measurement at the PT being more sensitive and more specific than measurement at the SFJ.

Table (10): Literature derived pre interventional GSV diameters measured at one of the sites studied in this survey and converted to the other site. Data are sorted according to diameter size.

\begin{tabular}{lcclcc}
\hline $\begin{array}{l}\text { Author treatment } \\
\text { investigated }\end{array}$ & Year & Number & Site of measurement & $\begin{array}{c}\text { SFJ } \\
\text { diameter }\end{array}$ & $\begin{array}{c}\text { Proximal } \\
\text { thigh diameter }\end{array}$ \\
\hline Pittaluga, P ASVAL & 2009 & 303 & SFJ & $7.1 \pm 0.2$ & $4.0 \pm 0.4$ \\
Gonzalez-Zeh Foam & 2008 & 53 & SFJ & $7.6 \pm 3.0$ & $4.3 \pm 1.7$ \\
Theivacoumar LASER & 2008 & 84 & SFJ & $7.7 \pm 2.0$ & $4.4 \pm 1.1$ \\
Theivacoumar LASER & 2008 & 27 & SFJ & $7.9 \pm 1.6$ & $4.5 \pm 0.9$ \\
Gonzalez-Zeh LASER & 2008 & 45 & SFJ & $8.2 \pm 3.2$ & $4.6 \pm 1.8$ \\
Pittaluga, P HLS & 2009 & 270 & SFJ & $8.4 \pm 0.3$ & $4.8 \pm 0.5$ \\
Creton Closure Fast & 2010 & 295 & SFJ & $8.4 \pm 2.3$ & $4.8 \pm 1.3$ \\
Pannier LASER & 2010 & 85 & SFJ & $10.0 \pm 0.4$ & $5.7 \pm 0.2$ \\
This study & 2010 & 122 & SFJ and proximal thigh & $10.9 \pm 3.9$ & $6.3 \pm 1.9$ \\
Parés Stripping & 2010 & 167 & Proximal thigh & $11.5 \pm 1.1$ & $6.5 \pm 1.9$ \\
Cappelli CHIVA & 2000 & 177 & Proximal thigh & $11.7 \pm 1.0$ & $6.7 \pm 1.7$ \\
Doganci LASER & 2010 & 54 & SFJ & $11.8 \pm 4.1$ & $6.7 \pm 7.3$ \\
Parés CHIVA & 2010 & 167 & Proximal thigh & $12.0 \pm 1.1$ & $6.8 \pm 2.0$ \\
Doganci LASER & 2010 & 52 & SFJ & $12.1 \pm 4.3$ & $6.8 \pm 7.6$ \\
Cappelli CHIVA & 2000 & 77 & Proximal thigh & $12.4 \pm 1.1$ & $7.1 \pm 2.0$ \\
\hline
\end{tabular}

Table (11): GSV diameters measured at the SFJ and PT as a function of the presence and extent of reflux.

\begin{tabular}{lcccc}
\hline & Number & $\begin{array}{c}\text { SFJ } \\
\text { diameter }\end{array}$ & $\begin{array}{c}\text { Proximal } \\
\text { thigh diameter }\end{array}$ & $p$-value \\
\hline Group I (no GSV reflux) & 60 & $7.5 \mathrm{~mm} \pm 1.8$ & $3.7 \pm 0.9$ & $<0.001$ \\
Groups II \& III (GSV reflux) & 122 & $10.9 \mathrm{~mm} \pm 3.9$ & $6.3 \mathrm{~mm} \pm 1.9$ & $<0.001$ \\
Group II (thigh reflux only) & 51 & $10.5 \mathrm{~mm} \pm 3.2$ & $6.2 \mathrm{~mm} \pm 1.7$ & $<0.001$ \\
Group III (lower leg reflux) & 71 & $11.2 \mathrm{~mm} \pm 4.3$ & $6.3 \mathrm{~mm} \pm 2.1$ & $<0.001$ \\
\hline
\end{tabular}

In this study patients were classified into 5 groups:

Classified reflux according to the site of measurement, number of patients 100 , results were nearly equal as introduced by Mendoza et al., 2012 at SFJ and proximal thigh, measurement of GSV at knee joint can predict reflux if $>5.5 \mathrm{~mm}$.

REFL UX AT:

Table (12): Results of the study.

\begin{tabular}{ll}
\hline SFJ & $7.16 \pm 2.30$ \\
Proximal Thigh & $6.60 \pm 1.89$ \\
Distal Thigh & $6.12 \pm 1.63$ \\
KNEE & $5.78 \pm 1.60$ \\
Proximal Leg & $4.60 \pm 1.24$ \\
Mid Leg & $3.59 \pm 1.16$ \\
CFV & $11.51 \pm 1.28$ \\
\hline
\end{tabular}

Limitation of study: Duplex is operator dependant to avoid this conflict one operator do all cases, number of patients were 100 only, study target only patients came to vein clinic, no relation found between quality of life and diameter.

The paper adds: Sites to predict reflux not only at SFJ and proximal thigh, GSV measurement at knee joint can predict reflux, CFV reflux can be affected by superficial venous system reflux.

\section{Funding:}

No study sponsorship.

Conflict of interest:

None. 


\section{References}

1- MAURINS U., HOFFMANN B.H., LÖSCH C., JÖCKEL K.H., RABE E. and PANNIER F.: Distribution and prevalence of reflux in the superficial anddeep venous system in the general population e results from the bonn vein study. Germany J. Vasc. Surg., 48: 680-7, 2008.

2- E. MENDOZA A, W. BLÄTTLER and F. AMSLER: Great Saphenous Vein Diameter at the Saphenofemoral Junction and Proximal Thigh as Parameters of Venous Disease Class. European Society for Vascular Surgery, 2012.

3- MOWATT-LARSSEN E. and SHORTELL C.: CHIVA. Semin. Vasc. Surg., 23: 1 18-22, 2010.

4- ALMEIDA J.I., KAUFMAN J., GÖCKERITZ O., CHOPRA P., EVANS M.T., HOHEIM D.F., et al.: Radiofrequency endovenous Closure FASTversus laser ablation for the treatment of great saphenous vein reflux: A multicenter, single-blinded, randomized study (Recovery study). J. Vasc. Interv.-Radiol., 20: 752-9, 2009.

5- BREU F.X., GUGGENBICHLER S. and WOLLMANN J.C.: 2 nd European consensus meeting on foam sclerotherapy 2006. Tegernsee, Germany: VASA, S71: p. 3-29, 2008.

6- COLERIDGE-SMITH P., LABROPOULOS N., PARTSCH H., MYERS K., NICOLAIDES A. and CAVEZZI A.: Duplex ultrasound investigation of the veins in chronic venous disease of the lower limbs UIP consensus document. Part I. Basic principles. Eur. J. Vasc. Endovasc. Surg., 31: 83-92, 2006.

7- PARES O.: Varicose vein surgery: Stripping versus the CHIVA method. A randomized controlled trial. Ann. Surg., 251: 6 24-31, 2010.

8- EVANS C.J., ALLAN P.L., LEE A.J., BRADBURY A.W., RUCKLEY C.V. and FOWKES F.G.R.: Prevalence of venous reflux in the general population on duplex scanning: The Edinburgh Vein Study. J. Vasc. Surg., 28: 76776, 1998.

9- LABROPOULOS N., TIONGSON J., PRYOR L., TASSIOPOULOS A.K., KANG S.S., MANSOUR A. and BAKER W.H.: Definition of venous reflux in lowerextremity veins. J. Vasc. Surg., 38: 793-8, 2003.

10- LURIE F., COMEROTA A., EKLOF B., KISTNER R.L., LABROPOULOS N., LOHR J., MARSTON W., MEISSNER M., MONETA G., NEGLEN P., NEUHARDT D., PADBERG F. and WELSH H.J.: Multicenter assessment of venous reflux by duplex ultrasound. J. Vasc. Surg., 55: 437-45, 2012.

11-LATTIMER C.R., AZZAM M., KALODIKI E. and GEROULAKOS G.: Venous filling time using airplethysmography correlates highly with great saphenous vein reflux time using duplex. Phlebology, 29 (2): 90-7, 2014.

12- LATTIMER C.R., KALODIKI E., AZZAM M., et al.: Volume displacements from an incompetent great saphenous vein during a standardised Valsalva manoeuvre. Acta Phlebologica, 13 (1): 25-30, 2012 b.
13- KAHLE B., HENNIES F., BOLZ S. and PRITSCH M.: The Reproducibility of the Ratio of volume flow in the common femoral vein and artery (VAFI) for quantification of the severity of venous insufficiency. Vasa, 32: 199203, 2003.

14- RUDOLPHI P., HUNOLD P. and KAHLE B.: Quantitative Erfassung desSchweregrads der venösen Insuffi zienz anhand der Hämodynamik. Posterpräsentation, 54. DGPJahrestagung in Lübeck, 2012.

15- COLERIDGE-SMITH P., LABROPOULOS N., PARTSCH H., MYERS K., NICOLAIDES A. and CAVEZZI A.: Duplex ultrasound investigation of the veins in chronic venous disease of the lower limbsd UIP consensus document. Part I. Basic principles. Eur. J. Vasc. Endovasc. Surg., 31: 83-92, 2006.

16- MENDOZA E.: Duplex-Sonographie der oberflächlichen Beinvenen. Darmstadt: Steinkopff, 2006.

17- YAMAKI T., NOZAKI M., SAKURAI H., TAKEUCHI M., SOEJIMA K. and KONO T.: Comparison of manual compression release with distal pneumatic cuff maneuver in the ultrasonic evaluation of superficial venous insufficiency. Eur. J. Vasc. Endovasc. Surg., 32: 46 2-7, 2006.

18- PARES O.: Varicose vein surgery: Stripping versus the CHIVA method. A randomized controlled trial. Ann. Surg., 251: 6 24-31, 2010.

19-CAPPELLI M., MOLINO LOVA R., ERMINI S., TURCHI A., BONO G., BAHNINI A. and FRANCESCHI C.: Ambulatory conservative hemodynamic management of varicose veins: Critical analysis of results at 3 years. Ann. Vasc. Surg., 14: 376-84, 2000.

20- EKLOF B., RUTHERFORD R.B., BERGAN J.J., CARPENTIER P.H., GLOVICZKI P., KISTNER R.L., et al.: Revision of CEAP classification for chronic venous disorders (CVD). J. Vasc. Surg., 40: 12 48-52, 2004.

21- THEIVACUMAR N.S., DELLAGRAMMATICAS D., DARWOOD R.J., MAVOR A.I.D. and GOUGH M.J.: Fate of the great saphenous vein following endovenous laser ablation: Does re-canalisation mean recurrence? Eur. J. Vasc. Endovasc. Surg., 36: 21 1-5, 2008.

22- HACH W. and HACH-WUNDERLE V.: Die Rezirkulationskreise der primären Varikose e Pathophysiologische Grundlagen zur chirurgischen Therapie. Berlin: Springer Verlag, 1994.

23- THEIVACUMAR N.S., DELLAGRAMMATICAS D., MAVOR A.I.D. and GOUGH M.J.: Endovenous laser ablation: does standard above knee great saphenous vein ablation provide optimum results in patients with both above-and below-knee reflux? A randomized controlled trial. J. Vasc. Surg., 48: 17 3-8, 2008.

24- GIBSON K., MEISSNER M. and WRIGHT D.: Great saphenous vein diameter does not correlate with worsening quality of life scores in patients with great saphenous vein incompetence JVS online, 14 May, 2012. 


\section{قياس قطر الوريد الآكبر فى المناطق المختلفة وعلاقتها بالإرتجاع الوريلى في مرضى دوالى الساقين}

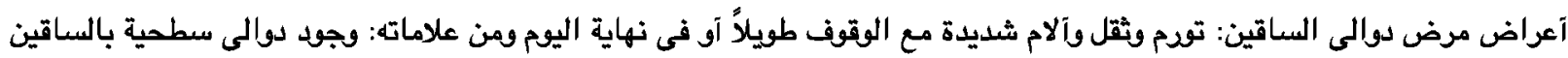

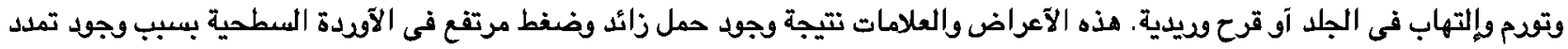

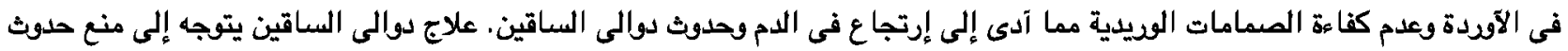

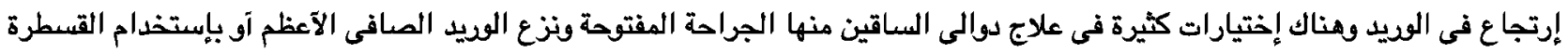

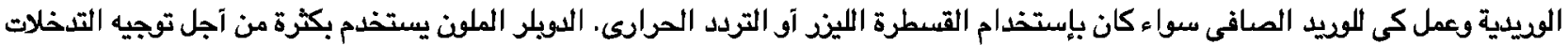

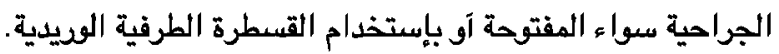

هدف البحث: البحث عن وجود علاقة بين قطر الوريد الصافى الآعظم وعلاقته بوجود إرتجاع فى الوريد فى المناطق المختلة فى الطرف

طريقة البحث: هدف الدراسة سوف تجرى على مائة طرف سفلى قدموا إلى عيادة جراحة الآوعية الدموية يشتكن من بوالى الساقين. تقسيم المرضى لست مجموعات، الآولى إرتجاع فى الإتصال بين الوريد الصافى الآعظم والوريد الفخذى، الثانية إرتجاع فى منطقة الفخذ،

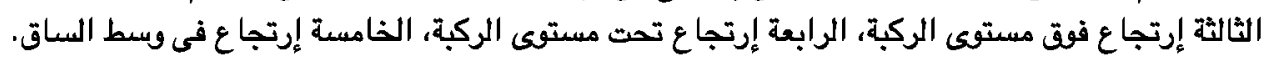

$$
\begin{aligned}
& \text { المرضى داخل نطاق البحث: } \\
& \text { ا- دوالى آولية في الطرف السفلى. } \\
& \text { r-1 } \\
& \text { المرضى خارج نطاق البحث: } \\
& \text { 1 - دوالى ثانوية ويوالى مرتدة. } \\
& \text { Y- وجود إرتجاع فى الآقددة العميقة. } \\
& \text { r- الحالات الحادة (إلتهاب خلوى - جلطة حادة) } \\
& \text { ع- آمراض الآوعية اللمفاوية. } \\
& \text { 0- الحمل. }
\end{aligned}
$$

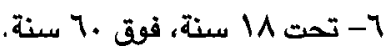

